\title{
2 Anthropogenic-driven alterations in black \\ 3 carbon sequestration and structure in a deep \\ 4 plateau lake
}

5 Changchun Huang ${ }^{*}, 1,2,3,4$, Lingfeng $\mathrm{Lu}^{1,4}, \mathrm{Yi} \mathrm{Li}^{1,4}$, Yao He ${ }^{1,4}$, Nana Shang ${ }^{1,4}$, Yixin

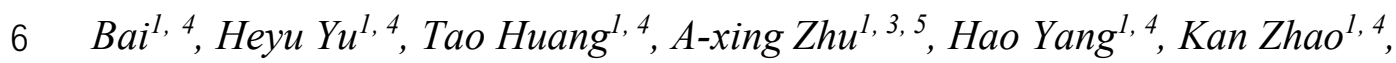

$7 \quad$ Yanhong $\mathrm{Yu}^{6}$

$8{ }^{1}$ Jiangsu Center for Collaborative Innovation in Geographical Information Resource

9 Development and Application, Nanjing Normal University, Nanjing 210023, China

${ }^{2}$ State Key Laboratory of Lake Science and Environment, Nanjing Institute of Geography and

11 Limnology, Chinese Academy of Sciences, Nanjing 210023, China

${ }^{3}$ Key Laboratory of Virtual Geographic Environment (Nanjing Normal University), Ministry of

Education, Nanjing 210023, China

${ }^{4}$ School of Geography Science, Nanjing Normal University, Nanjing 210023, China

${ }^{5}$ Department of Geography, University of Wisconsin, Madison, Wisconsin 53706, USA

${ }^{6}$ Yunnan Research Academy of Eco-environmental Science, Kunming, 650034, China 


\section{Text S1. Measurement of PAHs and $n$-alkane}

\section{PAHs extraction}

The sediment samples were extracted with $25 \mathrm{~mL}$ of $1 \mathrm{v} / 1 \mathrm{v}$ hexane/acetone by using the microwave extraction method and was then centrifuged for $15 \mathrm{~min}$ at $3000 \mathrm{rpm}$. The centrifugation process was repeated three times with $20 \mathrm{~mL}$ of $1 \mathrm{v} / 1 \mathrm{v}$ hexane/acetone, and then the total extracting solution was reduced to $1 \mathrm{~mL}$ by rotary evaporation. Then, the concentrated liquor was purified by using a chromatography column with $1 \mathrm{~g}$ of sodium sulfate and $1.5 \mathrm{~g}$ of 80 100 silica gel bottomed with $1.5 \mathrm{~g}$ of $100-200$ alumina. The final extracts were added to the column and were then eluted with $50 \mathrm{~mL}$ of $1 \mathrm{v} / 1 \mathrm{v}$ hexane/dichloromethane. Finally, this solution was reduced again to $1 \mathrm{~mL}$ by rotary evaporation. $\mathrm{PPAH} 16$ concentrations were measured by A Shimadzu QP2010plus gas chromatography-mass spectrometer (GC - MS). The chromatographic conditions were $250{ }^{\circ} \mathrm{C}$ for the injector temperature and $280{ }^{\circ} \mathrm{C}$ for the detector temperature. The mass spectrum was scanned from 45 to 600 in electron ionization mode at $70 \mathrm{eV}$ and then was scanned by using the selected ion monitoring mode ${ }^{1,2}$.

\section{n-alkane extraction}

The n-alkanes were obtained via microwave-assisted extraction $\left(100{ }^{\circ} \mathrm{C}, 10 \mathrm{~min}\right)$ from subsamples ( $2 \mathrm{~g})$, using a dichloromethane-methanol mixture (93:7, v:v). The supernatants were concentrated to $1 \mathrm{ml}$ by rotary evaporation at $40{ }^{\circ} \mathrm{C}$ after three centrifugations. The concentrated supernatants were purified and separated using solid-phase extraction $\left(\operatorname{Rtx}{ }^{\circledR} \sim 5 \mathrm{MS}, 30 \mathrm{~m} \times 0.32\right.$ $\mathrm{mm} \times 0.25 \mathrm{um}$ ) and $\mathrm{n}$-hexane, and then the eluent with $\mathrm{n}$-alkanes was concentrated to $1 \mathrm{ml}$. The $\mathrm{n}$-alkanes were quantified by measuring the concentrated eluent via gas chromatography mass spectrometry (GC/MS-QP2010 Ultra, Shimadzu Corp., Japan). The injection port temperature rose gradually to $300{ }^{\circ} \mathrm{C}$ at $10{ }^{\circ} \mathrm{C} \mathrm{min}{ }^{-1}$, starting at $50{ }^{\circ} \mathrm{C}^{3,4}$.

\section{Text S2. Geochronology and accumulation rate}

The ground samples (10 g) were sealed for a month to keep the ${ }^{226} \mathrm{Ra}$ and ${ }^{210} \mathrm{~Pb}$ in radioactive equilibrium. The activities of ${ }^{226} \mathrm{Ra}$ and ${ }^{210} \mathrm{~Pb}$ used in geochronology were measured using a high- resolution HPGe $\gamma$-spectrometer (EG\&GORTEC, GWL-120-15, USA) with 62\% relative detection efficiency and under $40,000 \mathrm{~s}$ determination time ${ }^{5}$. The activity of excess ${ }^{210} \mathrm{~Pb}$ $\left({ }^{210} \mathrm{~Pb}_{\mathrm{ex}}\right)$ calculated via subtract of ${ }^{226} \mathrm{Ra}$ from ${ }^{210} \mathrm{~Pb}$ was then used to date the sediment cores using the constant rate of ${ }^{210} \mathrm{~Pb}$ supply (CRS) model (Eq. 1$)^{6,7}$.

$$
\mathrm{t}=\frac{1}{\lambda} \ln \left(\frac{\mathrm{A}_{\mathrm{h}}}{\mathrm{A}_{0}}\right)
$$

where $\lambda$ is the decay constant of ${ }^{210} \mathrm{~Pb}, \mathrm{~A}_{\mathrm{h}}$ is the content of ${ }^{210} \mathrm{~Pb}$ ex at each sediment depth, and $\mathrm{A}_{0}$ is the total content of ${ }^{210} \mathrm{~Pb}$ in the sediment core. The specific activity of ${ }^{210} \mathrm{~Pb}_{\text {ex }}$ in the profile of all sediments ( 4 cores) ranged from 10.91 to $468.59 \mathrm{~Bq} \mathrm{Kg}^{-1}$, with a mean value of $82.67 \pm$ $65.62 \mathrm{~Bq} \mathrm{Kg}^{-1}$ (Figure S1). The period covered by each sedimentary core is longer than 100 years (the period of 1880 to 2017 for four cores is shown in Figure S1).

The accumulation rates (AR) of $\mathrm{BC}$ and PAHs were determined using the following equation (Eq. 2):

$$
A R=\frac{\rho * \partial Z / \partial t}{\partial t} * \delta
$$


where $\mathrm{t}$ is time (years), $\mathrm{Z}$ is depth $(\mathrm{cm}), \rho$ is the dry bulk density $\left(\mathrm{g} \mathrm{cm}^{-3}\right)$ and $\delta$ is the concentration of $\mathrm{BC}$ and PAHs.

\section{Text S3. Source identification and PMF analyses}

\section{Source identification}

The total n-alkane concentration $\left(C_{\mathrm{n} \text {-alkane }}\right)$ was expressed as the sum of the endmembers of n-alkane concentration $\left(C_{\mathrm{n} \text {-alkane-e }}\right)$ with each contribution $\left(P_{\mathrm{i}}\right)$, described as

$$
C_{n \text {-alkanes }}=\sum_{i=1}^{n}\left(C_{n \text {-alkanes-e }} \times p_{\mathrm{i}}\right) \quad \sum_{i=1}^{n} p_{\mathrm{i}}=1
$$

where $n$ is the number of n-alkane endmembers. $P_{\mathrm{i}}$ was solved by a multiple programming solver program with constraint condition of $P_{\mathrm{i}}$ between 0 and 1 . The flowing equation was the optimal target equation for the $P_{\mathrm{i}}$ solution:

$$
\operatorname{Min}\left[\left(\left(C_{n \text {-Alkanes-modeled }}-C_{n \text {-Alkanes-meansured }}\right) / C_{n \text {-Alkanes-meansured }}\right)^{2}\right]
$$

where $C_{\mathrm{n} \text {-alkane-modeled }}$ is the modeled n-alkane concentration from Eq. (1). $C_{\mathrm{n} \text {-alkane- }}$ measured denotes the measured n-alkane concentration of samples. The rationality of the endmember was examined by the estimation of the $P_{\mathrm{i}}$ without the constraint condition of that sum of $P_{\mathrm{i}}$ equal to 1 and $P_{\mathrm{i}}$ between 0 and 1 . The endmembers of autochthonous and allochthonous are reasonable if the sum of $P_{\mathrm{i}}$ close to 1 and $P_{\mathrm{i}}$ between 0 and 1 (Figure S4a). And then, the reasonable endmembers were used to estimate the via the $\mathrm{Eq}(3)$ and $\mathrm{Eq}(4)$. The consistent between estimated and measured $\mathrm{n}$-alkane was used to evaluate the estimation results (Figure S4b).

PMF analyses

The PAH source analysis was processed by the positive matrix factorization (PMF) model; this model has been widely applied for the assessment of source contributions and was proposed by the United Stated Environmental Protection Agency (USEPA). The principle of PMF is similar to the mass balance equation, which may be described as

$$
C_{\mathrm{PAHs}}=\sum_{i=1}^{n}\left(C_{\mathrm{PAHs}-\mathrm{Ci}} \times f_{\mathrm{i}}\right)+\varepsilon
$$

where $C_{\mathrm{PAHs}}$ is the total concentration of PAHs; $C_{\mathrm{PAHs}-\mathrm{Ci}}$ is the concentration of each source; $f_{i}$ is the contribution of each source to the total concentration of PAHs (factor in figure 6); $\varepsilon$ is the residual of each sample; and $n$ is the number of sources included in the analysis. The optimization objective function of the PMF solution is to minimize the difference between the measured and modeled $C_{\mathrm{PAHs}}$ from Eq. (3) for all samples.

Table S1 the range and mean value of BC, Char and Soot pre-1960s and post-2000 for four cores

\begin{tabular}{cccc}
\hline Types & Time range & Mean $\pm \mathrm{SD}\left(\mathrm{g} \cdot \mathrm{m}^{-2} \mathrm{y}^{-1}\right)$ & Range $\left(\mathrm{g} \cdot \mathrm{m}^{-2} \mathrm{y}^{-1}\right)$ \\
\hline $\mathrm{BC}$ & $\sim 1960$ & $0.96 \pm 0.64$ & $0.10-4.20$ \\
\hline
\end{tabular}




\begin{tabular}{cccc}
\hline & $2000-2017$ & $4.83 \pm 1.25$ & $3.38-7.32$ \\
\multirow{3}{*}{ Char } & $\sim 1960$ & $0.89 \pm 0.56$ & $0.09-3.67$ \\
& $2000-2017$ & $4.21 \pm 1.05$ & $2.84-6.43$ \\
\multirow{2}{*}{ Soot } & $\sim 1960$ & $0.12 \pm 0.08$ & $0.01-0.58$ \\
& $2000-2017$ & $0.64 \pm 0.23$ & $0.48-0.91$ \\
\hline
\end{tabular}

95

96

97 98

Table S2 the range and mean value of $\mathrm{BC}$, Char and Soot for each core

\begin{tabular}{cccc}
\hline Core & Types & Mean \pm SD $\left(\mathrm{mg} \mathrm{g}^{-1}\right)$ & Range $\left(\mathrm{mg} \mathrm{g}^{-1}\right)$ \\
\hline \multirow{4}{*}{ Core1 } & BC & $0.70 \pm 0.58$ & $0.11-4.18$ \\
& Char & $0.61 \pm 0.50$ & $0.08-3.61$ \\
& Soot & $0.10 \pm 0.08$ & $0.02-0.59$ \\
Core2 & BC & $1.07 \pm 0.50$ & $0.48-3.57$ \\
& Char & $0.92 \pm 0.43$ & $0.39-3.07$ \\
& Soot & $0.16 \pm 0.05$ & $0.08-0.5$ \\
Core3 & BC & $1.19 \pm 0.41$ & $0.40-2.65$ \\
& Char & $1.04 \pm 0.38$ & $0.31-2.18$ \\
& Soot & $0.15 \pm 0.08$ & $0.05-0.61$ \\
& BC & $1.70 \pm 0.90$ & $0.05-0.47$ \\
& Char & $1.58 \pm 0.76$ & $0.76-4.34$ \\
& Soot & $0.13 \pm 0.13$ & $0.81-4.95$ \\
\hline
\end{tabular}

Table S3 the range and mean value of PAHs for each core

\begin{tabular}{|c|c|c|c|c|}
\hline \multirow[t]{2}{*}{ Core } & \multirow[t]{2}{*}{ Types } & \multicolumn{2}{|c|}{$\begin{array}{c}\text { Concentration } \\
\left(\mathrm{ng} \mathrm{g}^{-1}\right)\end{array}$} & \multirow{2}{*}{$\begin{array}{c}\text { accumulation rate } \\
\left(\mathrm{mg} \cdot \mathrm{m}^{-2} \mathrm{y}^{-1}\right) \\
\text { Mean } \pm \mathrm{SD}\end{array}$} \\
\hline & & Mean \pm SD & Range & \\
\hline \multirow{4}{*}{ Core 1} & PAHs & $453.30 \pm 222.64$ & $94.18-1041.69$ & $1.59 \pm 0.94$ \\
\hline & $2+3$-rings & $312.51 \pm 189.82$ & $54.84-922.40$ & $1.05 \pm 0.65$ \\
\hline & 4-ring & $99.83 \pm 47.63$ & $24.62-255.95$ & $0.38 \pm 0.25$ \\
\hline & 5+6-rings & $40.96 \pm 36.82$ & $1.14-191.91$ & $0.16 \pm 0.17$ \\
\hline \multirow{4}{*}{ Core2 } & PAHs & $127.14 \pm 56.12$ & $25.29-402.89$ & $0.47 \pm 0.32$ \\
\hline & 2+3-rings & $74.87 \pm 37.53$ & $7.61-242.39$ & $0.27 \pm 0.20$ \\
\hline & 4-ring & $38.34 \pm 19.79$ & $5.58-140.68$ & $0.14 \pm 0.10$ \\
\hline & 5+6-rings & $13.94 \pm 7.14$ & $3.39-39.20$ & $0.06 \pm 0.04$ \\
\hline \multirow{4}{*}{ Core3 } & PAHs & $436.24 \pm 249.99$ & $54.63-1005.35$ & $1.11 \pm 0.67$ \\
\hline & $2+3$-rings & $290.56 \pm 193.21$ & $45.34-757.01$ & $0.74 \pm 0.44$ \\
\hline & 4-ring & $100.20 \pm 58.48$ & $4.55-282.86$ & $0.27 \pm 0.18$ \\
\hline & 5+6-rings & $45.48 \pm 61.28$ & $0.02-340.61$ & $0.11 \pm 0.12$ \\
\hline \multirow{4}{*}{ Core4 } & PAHs & $256.54 \pm 114.31$ & $56.25-481.73$ & $0.35 \pm 0.22$ \\
\hline & $2+3$-rings & $171.91 \pm 94.33$ & $33.53-357.78$ & $0.23 \pm 0.17$ \\
\hline & 4-ring & $51.29 \pm 30.97$ & $10.05-124.16$ & $0.06 \pm 0.04$ \\
\hline & 5+6-rings & $36.23 \pm 17.57$ & $4.59-72.69$ & $0.05 \pm 0.03$ \\
\hline
\end{tabular}

Table S4 the slopes between char and soot in different study areas 


\begin{tabular}{cccc}
\hline Study areas & Slopes & $\boldsymbol{R}^{2}$ & References \\
\hline Fuxian & 0.141 & 0.71 & This study \\
Gokyo & 0.196 & 0.85 & 8 \\
Yellow Sea northern & 0.254 & 0.93 & 9 \\
Eastern China Sea 2 & 0.229 & 0.71 & 8 \\
Lingge Co & 0.490 & 0.86 & 10 \\
Pumoyum Co & 0.338 & 0.46 & 11 \\
Qinghai Lake & 0.54 & 0.56 & 12 \\
southern & 0.099 & 0.67 & 13 \\
Bohai1 & 0.093 & 0.47 & 13 \\
Gonghai Lake & 0.118 & 0.56 & 9 \\
Mayinghai Lake & 0.13 & 0.50 & 8 \\
Eastern China Sea 1 & 0.150 & 0.04 & \\
Ranwu & 0.161 & 0.16 & 11 \\
Qiangyong Co & -0.066 & 0.01 & 8 \\
Tanglha & -0.162 & 0.12 & 9 \\
northern Qinghai & -0.387 & 0.00 & \\
Lake & 0.127 & 0.24 & \\
Gosainkunda & -0.004 & 0.00 & \\
Yellow Sea southern & & & \\
Bohai2 & & & \\
\hline
\end{tabular}

101

Figure $\mathrm{S} 1$ Vertical distribution of ${ }^{210} \mathrm{~Pb}$ ex for each core. The geochronology of the sediment cores was estimated from the ${ }^{210} \mathrm{~Pb}_{\mathrm{ex}} \mathrm{CRS}$ model.
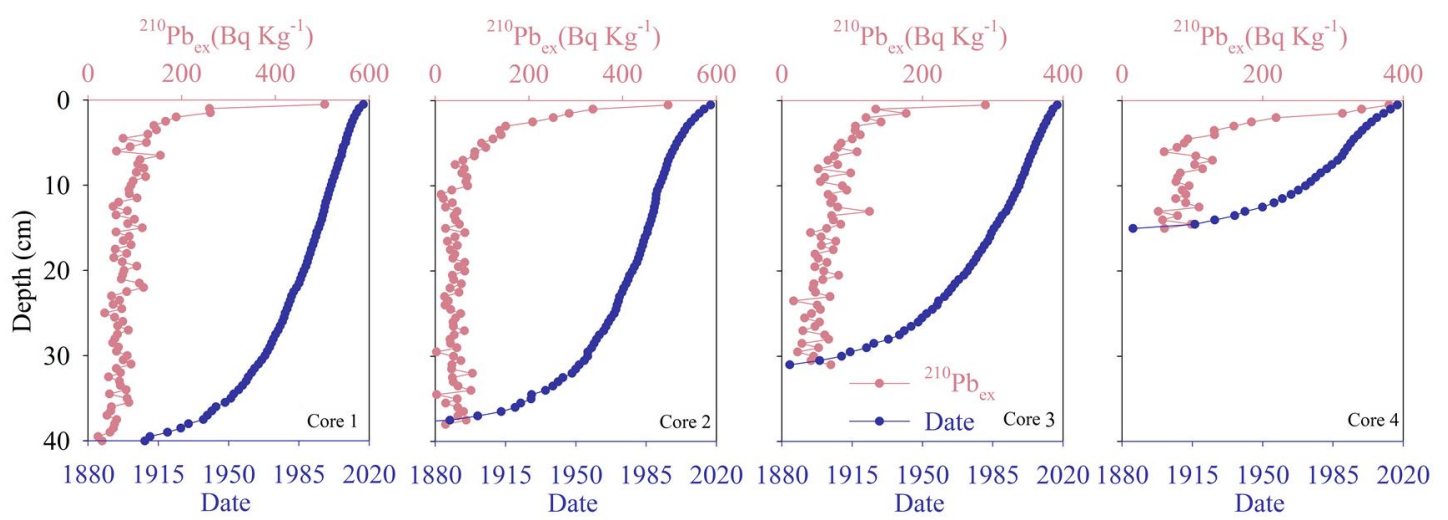

Figure S2 The bar graphs denote the percentage distributions of the 2- and 3-ringed PAHs, 4ringed PAHs, and 5- and 6-ringed PAHs. 

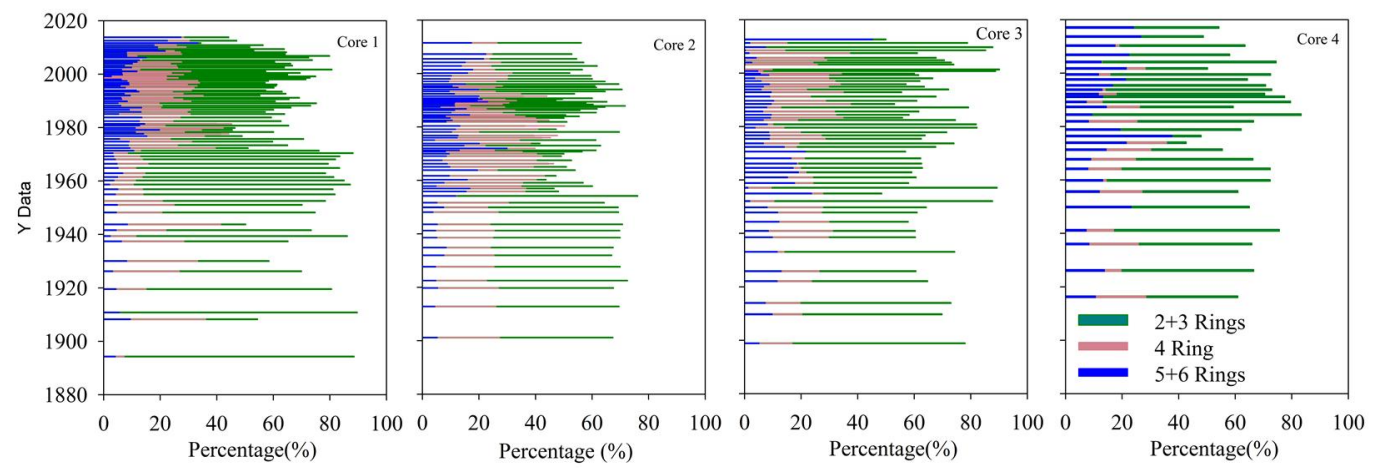

Figure S3 Correlation coefficients between Energy and mean value of $\mathrm{BC}$ are 0.96 (energy), 0.90(coal), 0.97(gasoline), 0.96(diesel),0.92(vehicles). the partial correlation coefficients between Gasoline, Vehicles and $\mathrm{BC}$ are $0.77,0.51$. the relationship between $\mathrm{BC}$ and date is $\mathrm{BC}=$ $0.0725 * \mathrm{e}^{0.03(\mathrm{Y}-1860)}\left(R^{2}=0.75, \mathrm{~N}=260\right)$ indicating the high increasing rate of $\mathrm{BC}$.
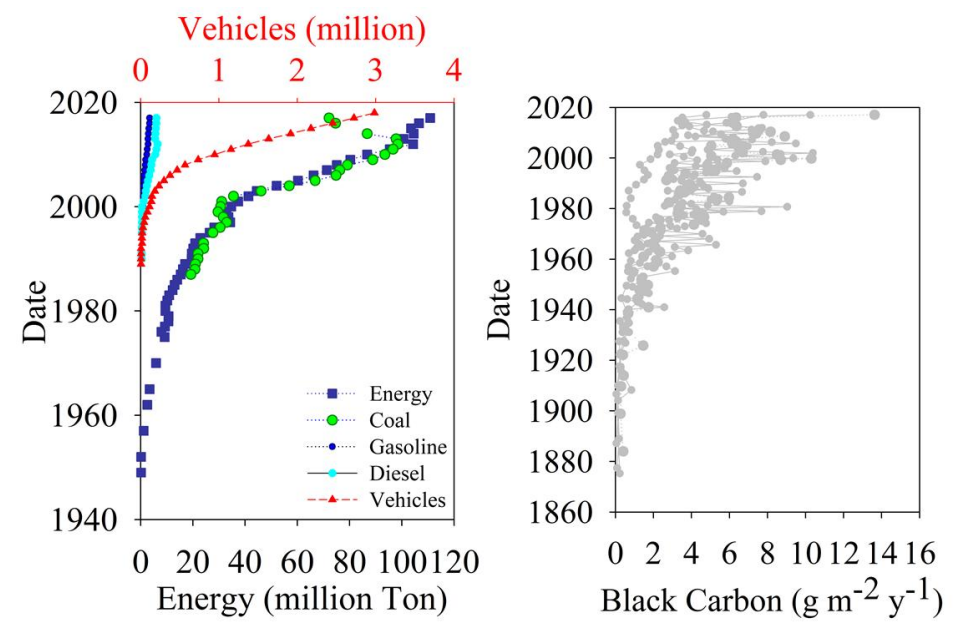

Figure S4 a presents the relationship between estimated percentage of autochthonous and allochthonous $\mathrm{OC}$ for the examination of endmember rationality; $b$ presents the high correlation between measured and estimated $\mathrm{n}$-alkane concentration.
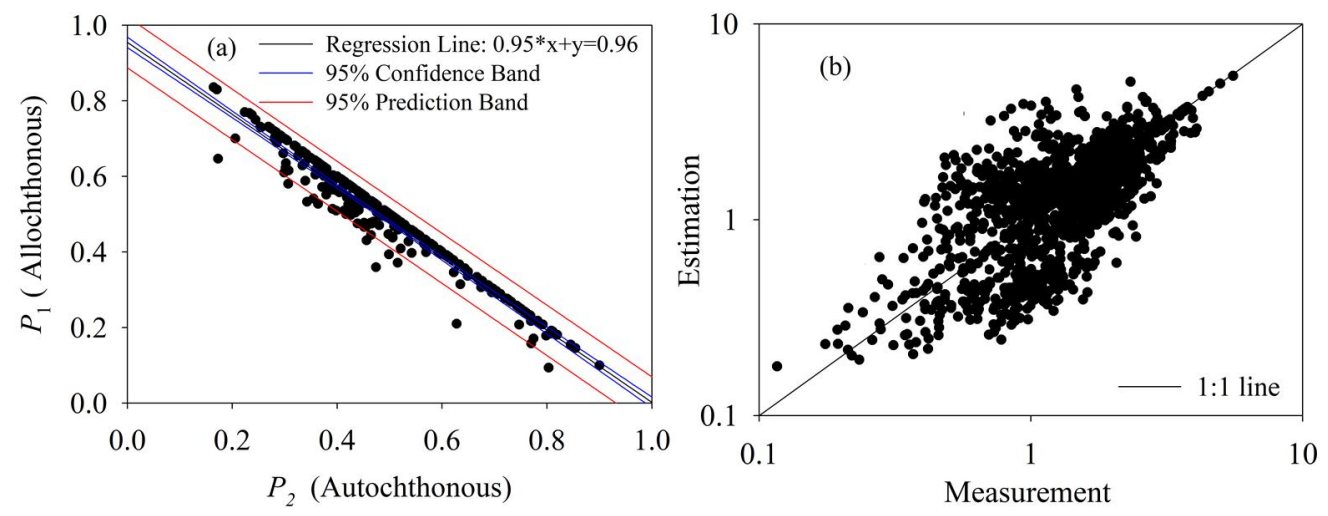

\section{Reference}

[1] Ma, X.H., Han, X.X., Jiang, Q.L., Huang, C.C., Huang, T., Yang, H., Yao, L. (2018).

Historical records and source apportionment of polycyclic aromatic hydrocarbons over the 
past 100 years in Dianchi Lake, a plateau lake in Southwest China. Archives of Environmental Contamination and Toxicology, 75:187-198.

[2] Zhang, Q.Q., Xia, Z.H., Wu, M.M., Wang, L.P., Yang, H. (2017). Human health risk assessment of DDTs and HCHs through dietary exposure in Nanjing, China. Chemosphere, 177:211-216.

[3] Gao, L., Hou J., Toney J., MacDonald D., Huang Y. (2011). Mathematical modeling of the aquatic macrophyte inputs of mid-chain n-alkyl lipids to lake sediments: implications for interpreting compound specific hydrogen isotopic records. Geochimica et Cosmochimica Acta, 75:3781-3791.

[4] Liu, H., Liu, W.G. (2016). n-Alkane distributions and concentrations in algae, submerged plants and terrestrial plants from the Qinghai-Tibetan Plateau. Organic Geochemistry, 99:10-22.

[5] Huang, C.C., Yao, L., Zhang, Y.L., Huang, T., Zhang, M.L., Zhu, A.X., Yang, H. (2017). Spatial and temporal variation in autochthonous and allochthonous contributors to increased organic carbon and nitrogen burial in a plateau lake. Science of the Total Environment, 603-604:390-400.

[6] Appleby, P.G. (2008). Three decades of dating recent sediments by fallout radionuclides: a review. Holocene, 18:83-93.

[7] Sanchez-Cabeza, J.A., Ruiz-Fernández, A.C. (2012). ${ }^{210} \mathrm{~Pb}$ sediment radiochronology: an in-tegrated formulation and classification of dating models. Geochim Cosmochim Acta, 82:183-200.

[8] Neupane, B., Kang, S.C., Chen, P.F., Zhang, Y.L., Ram, K., Rupakheti, D., Tripathee, L., Sharma, C.M., Cong, Z.Y., Li, C.L., Hou, J.Z., Xu, M., Thapa. P. (2019). Historical black carbon reconstruction from the lake sediments of the Himalayan-Tibetan Plateau. Environmental Science and Technology, 53: 5641-5651.

[9] Fang, Y., Chen, Y.J., Lin, T., Hu, L.M., Tian, C.G., Luo, Y.M., Yang, X., Li, J., Zhang, G. (2018). Spatiotemporal trends of elemental carbon and char/soot ratios in five sediment cores from Eastern China marginal seas: indicators of anthropogenic activities and transport patterns. Environmental Science and Technology, 52:9704-9712.

[10] Lin H., Wang, X.P., Gong, P., Ren, J., Wang, C.F., Yuan, X.H., Wang, L., Yao, T.D. (2017). The influence of climate change on the accumulation of polycyclic aromatic hydrocarbons, black carbon and mercury in a shrinking remote lake of the southern Tibetan Plateau. Science of the Total Environment, 601-602:1814-1823.

[11] Han, Y.M., Wei, C., Bandowe, B.A.M., Wilcke, W., Cao, J.J., Xu, B.Q., Gao, S.P., Tie, X.X., Li, G.H., Jin, Z.D., An, Z.S. (2015). Elemental carbon and polycyclic aromatic compounds in a 150-year sediment core from lake Qinghai, Tibetan plateau, China: influence of regional and local sources and transport pathways. Environmental Science and Technology, 49:4176-4183.

[12] Fang, Y. (2016). Regional Geochemical Behavior of Black Carbon in Bohai and Yellow Seas, China. Doctor degree of Environmental Science (PHD), Yantai Institute of Coastal Zone Research Chinese Academy of Sciences.

[13] Zhan, C.L., Wan, D.J., Han, Y.M., Zhang, J.Q. (2019). Historical variation of black carbon and PAHs over the last 200 years in central North China: Evidence from lake sediment records. Science of the Total Environment, 690:891-899. 